\title{
MANEJO DA QUEIMA DAS FLORES E DA PODRIDÃO-PARDA DO PESSEGUEIRO CULTIVADO EM SISTEMA ORGÂNICO ${ }^{1}$
}

\author{
GENUINO NEGRI ${ }^{2}$, LUIZ ANTÔNIO BIASI ${ }^{3}$, JOÃO AMÉRICO WORDELL FILHO ${ }^{4}$ \\ LOUISE LARISSA MAY-DE MIO
}

RESUMO - O presente trabalho objetivou avaliar o uso de fosfitos, iodo, calda sulfocálcica e Trichothecium roseum no manejo da Queima das flores e da Podridão-Parda do pessegueiro, doenças causadas por Monilinia fructicola, nas cultivares Granada e Chimarrita, em cultivo orgânico. Os tratamentos foram: 1) calda sulfocálcica + iodo (aplicada na floração e na pré-colheita); 2) alternância entre calda sulfocálcica + iodo, fosfito de $\mathrm{CaB}$ e T. roseum (aplicados na floração) e Fosfito de K e T. roseum (aplicados na pré-colheita); 3) T. roseum (aplicado na floração e na pré-colheita); 4) testemunha. Os tratamentos foram paralisados uma semana antes do início da colheita. A doença foi quantificada pela incidência da doença nas fases de floração, de frutos verdes, de colheita e de pós-colheita. A incidência da doença na testemunha, na fase de floração, variou de 22 a $72 \%$; nos frutos verdes, de 19 a 30\%, e na colheita, de 18 a $61 \%$. Todos os tratamentos reduziram a doença nas fases de floração e de frutos verdes, em ambas as cultivares, na ordem de 49 a $73 \%$ na floração e de 57 a $84 \%$ na fase de frutos verdes em relação à testemunha. Resultados significativos foram obtidos também em pós-colheita, na cultivar Granada, com reduções da doença em 54\% no tratamento 1, e $30 \%$ no tratamento 2 . Nenhum dos tratamentos foi eficiente na redução da incidência da doença na colheita. Termos para indexação: Monilinia fructicola, calda sulfocálcica, fosfitos, Trichothecium roseum, infecção latente.

\section{MANAGEMENT OF BLOSSON BLIGHT AND BROWN ROT PEACH DISEASES IN ORGANIC SYSTEMS}

\begin{abstract}
The aim of this work was to test the use of phosphites, lime sulfur, iodine and Trichothecium roseum, in the management of blossom blight and brown rot peach diseases, caused by Monilinia fructicola in Granada and Chimarrita cultivars, in organic systems. The treatments were: 1) lime sulfur + iodine (sprayed in blooming and pre-harvest); 2) alternating treatments between lime sulfur + iodine, $\mathrm{CaB}$ phosphites and $T$. roseum (sprayed in blooming), $\mathrm{K}$ phosphite and T. roseum (sprayed in pre-harvest); 3) T. roseum (sprayed in blooming and in pre-harvest); 4) control (no- treatment). The treatments were applied until one week before the first harvest. The incidence of the diseases was quantified at blooming, green fruits, harvest and post-harvest. The incidence of the diseases in the control treatment ranged from 22 to $72 \%$ at blooming, 19 to $30 \%$, at green fruits and 18 to $61 \%$ at harvest. All treatments reduced the disease incidence at blooming (49 to $73 \%$ ) and green fruit (57 to $84 \%$ ) comparing to the control, for both cultivars. Significant results were obtained for post-harvest in Granada cultivar with $54 \%$ reductions of disease incidence in treatment 1 , and $30 \%$ in treatment 2 . None of the treatments were efficient to reduce the disease at harvesting.
\end{abstract}

Index terms: Monilinia fructicola, lime sulfur, phosphites, Trichothecium roseum, latent infection.

\footnotetext{
${ }^{1}$ Trabalho Sinfruit 055 - Simpósio Internacional de Fruticultura - Avanços na Fruticultura (17 a 21 Outubro) Parte da tese de doutorado do primeiro autor

${ }^{2}$ Licenciado em Ciências Agrárias, Biólogo, Dr. Professor do Instituto Federal Catarinense, Rua Ladeira Fortaleza 270, Rio do Sul-SC. CEP. 89.160.000. E-mail: genunegri@hotmail.com

${ }^{3}$ Eng $^{\circ}$ agr $^{\circ}$, Dr. Professor do Programa de Pós-Graduação em Agronomia, Dept. de Fitotecnia, CCA/UFPR, Curitiba-PR. biasi@ufpr.br

${ }^{4}$ Dr. Pesquisador da EPAGRI, Chapecó-SC. E-mail: wordell@epagri.rct-sc.br

${ }^{5} E_{n}{ }^{a} a_{r}{ }^{a}$, Dra. Professora do Programa de Pós-Graduação em Agronomia, Dept. de Fitotecnia, CCA/UFPR, Curitiba-PR.

E-mail:maydemio@ufpr.br
} 


\section{INTRODUÇ̃̃O}

A Podridão-Parda, causada por Monilinia fructicola (G. winter) Honey, é a principal doença do pessegueiro, Prunus persicae (L.) Batsch, afetando flores (Queima de flores) e ramos, podendo também estar latente em frutos, na fase de desenvolvimento, sem apresentar sintomas visíveis, porém manifestando-se posteriormente durante a colheita e em pós-colheita (BYRDE; WILLETS, 1977; MAY DE MIO et al., 2008b). A doença está dispersa em todas as regiões de clima temperado do mundo, onde se cultiva o pessegueiro e outras rosáceas.

O manejo da Podridão-Parda é baseado em produtos químicos (MAY-DE MIO et al., 2008b). No entanto, além de estes causarem desequilíbrios ambientais, elevam o custo de produção e não garantem um manejo eficiente da doença, principalmente em casos de áreas sob alta pressão de inóculo, condições climáticas favoráveis e/ ou manejo cultural inadequado. Considerando a necessidade de se manter um período mínimo de carência entre a aplicação e o consumo das frutas para se evitar resíduos tóxicos prejudiciais à saúde humana, alguns produtos não podem ser utilizados no período da colheita, quando o inóculo da doença chega a níveis críticos e a suscetibilidade da fruta é maior, proporcionando rápido desenvolvimento do patógeno e aumento da doença de forma epidêmica (EMERY et al., 2002).

Sob condições favoráveis e cultivares suscetíveis à doença, mesmo com uso de fungicidas na fase de pós-colheita, os danos podem atingir níveis superiores a 50\% (HONG et al., 1998), ou até acima de $90 \%$, quando não tratada nas fases de colheita e pós-colheita (MOREIRA, 2005).

Com a expansão da agricultura orgânica, pesquisadores e produtores demonstraram maior interesse pela pesquisa com indutores de resistência, produtos menos agressivos ao ambiente e microrganismos antagônicos, como estratégia de manejo das doenças, em substituição aos fungicidas sintéticos (EMERY et al., 2002), além do problema com aparecimento de resistência a estes produtos (HOLB; SCHNABEL, 2008). Dentre os produtos alternativos para uso na produção orgânica, os fosfitos, que são adubos foliares à base de micronutrientes, são indicados por atuarem diretamente sobre patógenos (FENN; COFFEY, 1985) ou pela ativação de mecanismos de defesa, estimulando a produção de fitoalexinas (JACKSON et al., 2000; SÕNEGO; GARRIDO, 2005) de lignina e de fenóis (NOJOSA et al., 2005).
Os fosfitos de cálcio e boro $(\mathrm{CaB})$ e de potássio $(\mathrm{K})$ foram testados em campo com resultados promissores para $M$. fructicola em pessegueiros (MOREIRA; MAY-DE MIO, 2009). Estes produtos foram também estudados no manejo de Oídio e Sarna da macieira (GEELEN, 1999) e Alternaria alternata no interior de frutos da macieria (REUVENI, 2003).

A calda sulfocálcica é um produto permitido pelo Ministério da Agricultura, Pecuária e Abastecimento (MAPA), conforme Instrução Normativa $\mathrm{n}^{\circ} 007$, de 17 de maio de 1999, para o uso na agricultura orgânica, que além de fornecer nutrientes às plantas, como cálcio e enxofre, apresenta efeito acaricida, fungicida e inseticida, sendo indicada para manejo fitossanitário em diversas espécies frutíferas (SÔNEGO; GARRIDO, 2005; ALMIRI et al., 2010). Atualmente, a calda sulfocálcica, em baixas concentrações, é indicada para manejo de doenças fúngicas em diversas culturas, inclusive as hortícolas (ALMIRI et al. 2010), mas, para pessegueiro no Brasil, as informações são escassas.

O iodo também é permitido para uso na agricultura orgânica de acordo com a IN 007/1999 do MAPA e é utilizado com sucesso em Santa Catarina, no manejo da Sarna da macieira, sendo indicado pela Empresa de Pesquisa Agropecuária e Extensão Rural - EPAGRI, para manejo de $M$. fructicola, associado à calda sulfocálcica, em baixas concentrações. Esta recomendação foi obtida por comunicação pessoal, entretanto nenhum dado na literatura foi encontrado para dar suporte a esta estratégia.

Em relação ao controle biológico de $M$. fructicola, a maioria das pesquisas foi direcionada para pós-colheita e intensificadas a partir da década de 90. Vários antagonistas, como Trichoderma atroviride (Karsten), Trichoderma viride (Persoon: Fries), Rhodotorula sp. foram utilizados no manejo da M. fructicola, nos EUA (HONG et al., 1998; MERCIER; JIMÉNEZ, 2004), e Trichothecium roseum (Pers.) Link no Brasil (MOREIRA et al., 2002). No manejo de espécie semelhante, a Monilinia laxa (Aderh. e Ruhl.) foi também testado o antagonista Epicoccum nigrum (Link) na Espanha, Itália e França (LARENA et al., 2005).

Este trabalho foi conduzido com o objetivo de elucidar formas de manejo da Queima das flores e da Podridão-Parda do pessegueiro para sistema orgânico, considerando a falta de dados que confirmem a eficiência da calda sulfocálcica e do iodo, bem como informações sobre o uso de fosfitos e do antagonista $T$. roseum neste sistema. 


\section{MATERIAL E MÉTODOS}

O experimento foi realizado no ano de 2004, em pomar de pessegueiro, conduzido em sistema orgânico, cultivares Granada e Chimarrita, localizado no município de Rio do Sul-SC, Brasil, cujas coordenadas geográficas são latitude: $27^{\circ} 11^{\prime} 07^{\prime \prime}$ S e longitude: $49^{\circ} 39^{\prime} 39^{\prime}$ 'W. As plantas possuíam sete anos de idade e espaçamento de $6,5 \times 5 \mathrm{~m}$, sendo conduzidas em forma de taça.

A descrição dos tratamentos, concentrações do ingrediente ativo, fases da cultura e datas de aplicação constam da Tabela 1. Para o tratamento 2, a aplicação dos produtos foi feita de forma alternada e na mesma data. As pulverizações foram realizadas nas fases de floração e pré-colheita, com o uso de pulverizador costal (Jacto com bico leque) capacidade para 20 L, utilizando-se, em média, de 3 $\mathrm{L}$ de calda por planta. O delineamento experimental foi em blocos casualizados, com três repetições e três plantas por parcela.

Para determinar a incidência de Queima das flores, foram efetuadas duas coletas de 50 flores totalmente abertas na planta central de cada parcela, sendo as coletas feitas 24 horas antes e após as pulverizações. As flores foram acomodadas em caixas tipo Gerbox ${ }^{\circledR}$, com vinte e cinco flores por caixa, forradas com papel-filtro esterilizado e umedecido em água esterilizada, utilizando-se de 25 flores por caixa, e mantidas em estufa BOD por três dias, a $25^{\circ} \mathrm{C}$, no escuro, e por mais três dias a $4^{\circ} \mathrm{C}$, com luz (LUO et al., 2001). A incidência de Podridão-Parda nas estruturas florais (cálice) foi verificada em microscópio estereoscópico.

Para verificar a presença de infecção latente de $M$. fructicola em frutos verdes da cultivar Grana$\mathrm{da}$, foram utilizados 50 frutos por parcela no início da frutificação e 20 frutos aos 45 dias antes da colheita. Para a cultivar Chimarrita, foram utilizados 20 frutos no início da frutificação e 10 frutos aos 45 dias antes da colheita. Os frutos foram coletados nas partes internas das duas plantas laterais de cada parcela. Para a quebra de resistência dos frutos verdes a fim de promover condições para a manifestação dos fungos, que por ventura estejam latentes no seu interior, estes foram sequencialmente imersos por um minuto nas soluções de etanol a $70 \%$, hipoclorito de sódio a $2 \%$ e paraquat a $2 \%$ de ingrediente ativo e, posteriormente, lavados em água esterilizada, conforme metodologia de Northover e Cerkauskas, 1994. Em seguida, foram colocados em bandejas plásticas de PVC, contendo papel-toalha umedecido em água esterilizada, as quais foram embaladas em sacos plásticos e man- tidas a $25^{\circ} \mathrm{C}$ por sete dias. Avaliou-se a incidência de infecção latente no $3^{\circ} \mathrm{e} 7^{\circ}$ dias após a incubação, sendo o resultado final obtido pelo somatório das duas avaliações.

A incidência da doença durante o período da colheita foi determinada pela proporção de frutos que apresentaram sintomas da doença em relação ao total de frutos colhidos. Para as avaliações em pós-colheita, os frutos foram coletados nas plantas centrais de cada parcela, sendo utilizados 50 frutos da cultivar Granada, divididos em duas coletas de 20 frutos e uma de 10 frutos. Para a cultivar Chimarrita, que apresentou baixo número de frutos por planta, foram utilizados 20 frutos, divididos em duas coletas de 10 frutos. Metade destes frutos foi imersa durante um minuto em solução de hipoclorito de sódio a $0,5 \%$ e, em seguida, lavado em água esterilizada. Os demais frutos não sofreram desinfestação superficial. Todos os frutos foram acomodados sobre mesas expostas à temperatura ambiente (entre 20 a $25^{\circ} \mathrm{C}$ ), forradas com papel-toalha, sendo a incidência avaliada no $7^{\circ}$ dia após a colheita.

O antagonista $T$. roseum foi isolado em 1997, a partir de pêssegos provenientes da região da Lapa-PR, sendo que sua eficiência no manejo da doença em pós-colheita foi testada por Moreira et al. (2002). A produção do inóculo inicial seguiu a metodologia adotada por Moreira (2005), sendo utilizada a concentração de $10^{6}$ conídios. $\mathrm{mL}^{-1}$.

Análise dos dados: A incidência da doença, em flores, frutos verdes e em frutos maduros durante a colheita e a pós-colheita, foi submetida à análise de variância, após transformação dos dados em $\ln \mathrm{x}$ ou em $\sqrt{X+1}$ utilizando-se do programa estatístico SAS (versão 9.1), sendo as médias dos tratamentos comparadas pelo teste " $\mathrm{t}$ ", a $5 \%$ de probabilidade. Para verificar a influência e/ou relação entre a doença nas fases avaliadas, foi realizada a regressão multilinear (para diversas variáveis quantitativas, para examinar efeito de uma sobre a outra) e resulta no coeficiente de determinação $\mathrm{R}$ e no valor de significância $p$. Além disso, o gráfico resultante fornece a correlação (medida do grau de associação entre as variáveis ou intensidade com que estas variam conjuntamente), resultando no coeficiente de correlação (r). Para estas análises, foi utilizado o programa Statistica 6.0, StatSoft, Tulsa, OK, USA.

\section{RESULTADOS E DISCUSSÃO}

Na fase de floração, a incidência da Queima das flores, antes das pulverizações, era alta e uni- 
forme em todos os tratamentos, variando de 43 a $58 \%$ na cultivar Granada (Tabela 2) e de 32 a $38 \%$ na cultivar Chimarrita (Tabela 3). Porém, após as pulverizações, ocorreram reduções significativas na incidência de $65 \%$ na cultivar Granada com o uso associado de todos os produtos (Tratamento 2) e de $73 \%$ na cultivar Chimarrita com $T$. roseum, em relação à testemunha. Estes resultados confirmam experiências desenvolvidas por Moreira e May-De Mio (2009) com fosfitos de $\mathrm{CaB}$ e de $\mathrm{K}$ e T. roseum. Durante a fase de crescimento dos frutos, os tratamentos apresentaram reduções significativas na incidência da doença de 68 a $84 \%$ no cultivar Granada e de 57 a $77 \%$ na cultivar Chimarrita, em relação à testemunha (Tabelas 2 e 3), sendo que o melhor tratamento na cultivar Granada foi a Calda Sulfocálcica e na cultivar Chimarrita o T. roseum.

O desenvolvimento da doença na fase de crescimento dos frutos, verificado nas plantas-testemunha da cultivar Chimarrita, bem como em maior incidência na cultivar Granada, em relação aos demais tratamentos (Tabelas 2 e 3 ), confirma a ocorrência da entrada de novas infecções nesta fase da cultura, conforme relatado por May-De Mio et al. (2008a), observando que na infecção pelo patógeno ocorre em frutos a partir de $0,6 \mathrm{~cm}$ de diâmetro até o amadurecimento, aumentando a incidência da doença com a idade do fruto. Além disso, Gell et al. (2008) verificaram que essas infecções têm relação direta com a densidade de conídios sobre os frutos e condições climáticas favoráveis. Esta situação determina a premente necessidade de tratamento dos frutos, além da adoção de práticas culturais que visem à redução do inóculo do fungo, nesta fase da cultura, para o cultivo orgânico, porque neste caso o inóculo geralmente é alto e frequente o tempo todo.

Durante o período da colheita, não foram verificadas diferenças significativas na incidência da doença entre os tratamentos. Nesta fase, a maior incidência de Podridão-Parda ocorreu no tratamento-testemunha, atingindo $18 \%$ na cultivar Granada e $61 \%$ na cultivar Chimarrita (Tabelas 2 e 3). No entanto, reduções na incidência da doença com os tratamentos atingiram $39 \%$ na cultivar Granada e 44\% na cultivar Chimarrita, em relação à testemunha. Tal fato indica a possibilidade de ajuste na época de aplicação, ampliando o uso dos produtos próximo da colheita ou ainda durante a mesma. A maior incidência da Podridão-Parda na fase de colheita do pêssego foi também constatada por Luo e Michailides (2003), afirmando que, nesta fase, o fungo $M$. fructicola se expressa com maior intensidade em virtude de condições climáticas ideais ao seu desenvolvimento. Outra razão deste crescimento pode ser devida à ativação das infecções latentes durante os processos de maturação e/ou senescência dos frutos (CRUICKSHANK; WADE, 1992). No caso específico deste experimento, pode ser atribuída à elevada pressão de inóculo no local proveniente de outras cultivares sem manejo da doença ou, ainda, à paralisação dos tratamentos uma semana antes da colheita.

Em pós-colheita, os frutos mantidos durante sete dias sob condições ambientes apresentaram incidência média de Podridão-Parda menor em frutos desinfestados do que em frutos não desinfestados, em ambas as cultivares, comprovando que contaminações durante a colheita, transporte e o armazenamento contribuem para a manifestação dos sintomas da doença nesta fase. Na cultivar Granada, ocorreu 26 a 57\% de incidência da doença em frutos desinfestados, contra 56 a $73 \%$ em frutos não desinfestados (Tabela 2), enquanto na cultivar Chimarrita de 60 a $73 \%$, em frutos desinfestados contra 73 a 90\% em frutos não desinfestados (Tabela 3). Nesta fase, a incidência em frutos desinfestados foi, provavelmente, devida às infecções latentes que ocorreram desde a fase da floração. Segundo Luo et al. (2001), estas infecções podem manter-se latentes no interior dos frutos aparentemente sadios e manifestam-se posteriormente na fase de pós-colheita.

No presente estudo, frutos da cultivar Granada, tratados com calda sulfocálcica e iodo ou integrado com fosfitos e $T$. roseum, foram diferentes da testemunha. Entretanto, o maior efeito foi provavelmente devido ao uso da calda e iodo, principalmente quando os frutos foram desinfestados. Para frutos não desinfestados, que acumularam todo o inóculo durante o processo da colheita, não houve diferença entre tratamentos. Para a Chimarrita, isso não ocorreu, provavelmente devido à pressão maior do inóculo no campo, que impediu a ação dos tratamentos. Lembrando-se que a cultivar Chimarrita é colhida logo após a Granada, sendo ainda considerada mais suscetível à doença, conforme afirmaram Raseira e Nakasu (2003), sendo esta característica atribuída à menor firmeza de polpa e maior teor de açúcar.

A ação dos fosfitos sobre doenças fúngicas foi confirmada por diversos autores, como Sônego e Garrido (2005), Geelen (1999) e Reuveni (2003). Outro trabalho desenvolvido por Moreira e May-De Mio (2009), utilizando fosfitos de $\mathrm{CaB}$ e de $\mathrm{K}$, em pré e pós-colheita, demonstraram sua eficiência no manejo da Podridão-Parda em pessegueiros. No presente estudo, a metodologia utilizada para 
a verificação deste tipo de infecção proporcionou condições para a manifestação do patógeno que normalmente não ocorre em campo, facilitando desta forma a avaliação da mesma.

A incidência de Podridão-Parda em pós-colheita foi também avaliada por Moreira (2005), atingindo $96 \%$, aos cinco dias da colheita, no tratamento-testemunha, e 50 a $62 \%$ nos frutos tratados na pré-colheita com T. roseum e Captan, e com fungicidas preconizados pela Produção Integrada de Pêssego do Paraná com a cultivar BR1. Da mesma forma que na colheita, a eficiência dos tratamentos na redução da incidência de Podridão-Parda em pós-colheita foi prejudicada pela elevada pressão do inóculo do fungo durante a colheita, proveniente de plantas não tratadas no local e período experimental, aumentando a infestação dos frutos colhidos.

A aplicação da calda sulfocálcica em baixas concentrações, no período vegetativo da cultura do pessegueiro, permitiu avaliar sua ação sobre $M$. fructicola, uma vez que é indicada, em maiores concentrações, como erradicante, quando aplicada no período de dormência de frutíferas (ALMIRI et al., 2010). A EPAGRI-SC, vem utilizando com sucesso a calda sulfocálcica $29{ }^{\circ} \mathrm{Be}$, diluída a $0,4 \%$, e associada ao iodo (2\%), diluído a $0,04 \%$, para o manejo da Sarna da ameixeira, causada por Cladosporium carpophylum Thuem (GONÇALVES et al., 2005). A empresa recomenda ainda o uso da calda sulfocálcica associada ao iodo para o manejo de Podridão-Parda em pessegueiro, porém os resultados que comprovam esta eficiência não foram publicados. Nenhum sintoma de fitotoxidez foi verificado em plantas tratadas com estes produtos e concentrações utilizadas neste experimento. Contudo, a partir dos resultados obtidos, vislumbra-se a possibilidade de seu emprego no manejo da Podridão-Parda nas fases de floração e de crescimento dos frutos do pessegueiro cultivado em sistema orgânico.

A ação positiva de $T$. roseum sobre $M$. fructicola, em flores de pessegueiro e frutos em desenvolvimento, observada no presente trabalho, confirma sua capacidade antagonista, conforme observado por Moreira et al. (2002). Pelos resultados obtidos no presente experimento, a utilização do fungo poderá ser indicada como alternativa biológica no manejo da doença nestas fases. Entretanto, para um próximo trabalho, recomendam-se pulverizações próximas e entre as colheitas para garantir a eficiência do antagonista nesta fase.

A análise de regressão multilinear e a correlação entre a incidência da Podridão-Parda e as fases do desenvolvimento do pessegueiro demonstraram várias combinações significativas de interação para a cv. Granada: flor x fruto verde, flor $\mathrm{x}$ pós-colheita, frutos verdes $\mathrm{x}$ pós-colheita, indicando a relação direta entre as infecções latentes, excluindo relações com a colheita. Para a cv. Chimarrita, foi observado apenas entre flor $\mathrm{x}$ fruto verde (Tabela 4).

A relação da incidência da doença com as fases de florescimento e de crescimento dos frutos pode ser explicada pela presença do fungo nas flores, que serve como fonte de inóculo para infecção de novos frutos, permanecendo latente no interior destes e manifestando-se posteriormente durante os processos de amadurecimento (BYRDE; WILLETS, 1977). A correlação entre a infecção latente com a manifestação dos sintomas da doença em pós-colheita parece mais fácil de compreender, pois alguns autores afirmam que o patógeno pode penetrar diretamente nos frutos verdes ou ficar entre os pelos da superfície dos frutos até a chegada da fase de maturação (BYRDE; WILLETS, 1977; LUO; MICHAILIDES, 2003; GELL et al., 2008).

Estudos epidemiológicos feitos nos Estados Unidos sobre a incidência de Podridão-Parda em pessegueiro confirmaram a existência de uma relação direta entre as fases finais de desenvolvimento dos frutos e a pós-colheita (EMERY et al., 2000). Estes dados também foram confirmados por May-De Mio et al. (2008a) com inoculações em campo de $M$. fructicola, sem ferimentos e com o controle das demais infecções, concluindo que frutos podem ser infectados a partir de $6 \mathrm{~mm}$ de diâmetro e que estas infecções permanecem latentes até a pós-colheita. 
TABELA 1- Tratamentos e concentração dos ingredientes ativos aplicados nas diferentes fases do desenvolvimento da cultura do pessegueiro cultivares Granada e Chimarrita, para o manejo da Queima das flores e da Podridão-Parda, causadas por Monilinia fruticola, em Santa Catarina, 2004.

\begin{tabular}{|c|c|c|c|}
\hline Tratamento & $\begin{array}{l}\text { Ingrediente ativo } \\
\text { mg. } \mathrm{L}^{-1} \text { ou conídios. } \\
\mathrm{mL}^{-1}\end{array}$ & $\begin{array}{l}\text { Fases da } \\
\text { cultura }\end{array}$ & Datas de aplicação \\
\hline 1- Calda Sulfocálcica e Iodo ${ }^{1}$ & $\begin{array}{l}0,90 \text { e } 0,006 \mathrm{mgL}^{-1} \\
0,12 \text { e } 0,006 \mathrm{mgL}^{-1}\end{array}$ & $\begin{array}{l}\text { - Floração } \\
\text { - Pré-colheita }\end{array}$ & $\begin{array}{l}-8-08,19-08 \text { e } 02-09 \\
-10-10,21-10,26-10,04-11 \text { e } 13-11\end{array}$ \\
\hline $\begin{array}{l}\text { 2- Calda Sulfocálcica + Iodo, } \\
\text { Fosfitos de } \mathrm{CaB}^{2} \text {, } \\
\text { Trichothecium roseum, } \\
\text { Fosfito de } \mathrm{K}^{3} \text {, } \\
\text { Trichothecium roseum }\end{array}$ & $\begin{array}{l}0,9 \text { e } 00,006 \mathrm{mgL}^{-1} \\
0,32 \mathrm{mgL}^{-1} \\
10^{6} \\
1,20 \mathrm{mgL}^{-1} \\
10^{6}\end{array}$ & $\begin{array}{l}\text { - Floração } \\
\text { - Floração } \\
\text { - Pré-colheita } \\
\text { - Pré-colheita } \\
\text { - Pré-colheita }\end{array}$ & $\begin{array}{l}-08-08 \\
-19-08 \text { e } 02-09 \\
-19-08 \text { e } 02-09 \\
-10-10,21-10,26-10,04-11 \text { e } 13-11 \\
-10-10,21-10,26-10,04-11 \text { e } 13-11\end{array}$ \\
\hline 3- Trichothecium roseum & $\begin{array}{l}10^{6} \\
10^{6}\end{array}$ & $\begin{array}{l}\text { - Floração } \\
\text { - Pré-colheita }\end{array}$ & $\begin{array}{l}-08-08,19-08 \text { e } 02-09 \\
-10-10,21-10,26-10,04-11 \text { e } 13-11\end{array}$ \\
\hline 4- Testemunha & Não tratado & |-------------- & |------------------- \\
\hline
\end{tabular}

${ }^{1}$ Calda Sulfocálcica (28o baumé) e Iodo ( $\left.2 \%\right) ;{ }^{2}$ Fosfito de Cálcio e Boro (equivalente a 10,7\% P2O5 + 3,89\% Ca $+0,51 \%$ B) e ${ }^{3}$ Fosfito de Potássio (equivalente a 40\% P2O5 + 20\% K2O).

TABELA 2 - Efeito de tratamentos na incidência (em porcentagem) de Monilinia fructicola em flores e em frutos, na cultura do pessegueiro cv. Granada, cultivado em sistema orgânico. Rio do Sul-SC, 2004.

\begin{tabular}{|c|c|c|c|c|c|c|}
\hline \multirow{2}{*}{ Tratamentos } & \multicolumn{2}{|c|}{ Floração } & \multirow[t]{2}{*}{$\begin{array}{l}\text { Frutos } \\
\text { verdes }\end{array}$} & Colheita & \multicolumn{2}{|c|}{ Pós-colheita } \\
\hline & Antes $^{1}$ & Após ${ }^{1}$ & & ós ${ }^{1}$ & Sem desinfestação & Desinfestados \\
\hline 1- Calda Sulfocálcica e Iodo & $43 \mathrm{~b}$ & $37 \mathrm{~b}$ & $3 \mathrm{~b}$ & $12 \mathrm{a}$ & $61 \mathrm{a}$ & $26 \mathrm{c}$ \\
\hline $\begin{array}{l}\text { 2- Calda Sulfocálcica e Iodo, } \\
\text { Fosfitos de CaB e de K, } \\
\text { Trichothecium roseum }\end{array}$ & $58 \mathrm{a}$ & $25 \mathrm{~b}$ & $4 \mathrm{~b}$ & $14 \mathrm{a}$ & $56 \mathrm{a}$ & $40 \mathrm{~b}$ \\
\hline 3- Trichothecium roseum & $46 \mathrm{~b}$ & $31 \mathrm{~b}$ & $6 \mathrm{~b}$ & $11 \mathrm{a}$ & $64 \mathrm{a}$ & $52 \mathrm{ab}$ \\
\hline 4- Testemunha & $40 \mathrm{~b}$ & $72 \mathrm{a}$ & $19 \mathrm{a}$ & $18 \mathrm{a}$ & $73 \mathrm{a}$ & $57 \mathrm{a}$ \\
\hline Média & & & & & $64 \mathrm{~A}$ & $44 \mathrm{~B}$ \\
\hline $\mathrm{CV}(\%)$ & 10 & 4,7 & 1 & 4,9 & 31,7 & 15,1 \\
\hline
\end{tabular}

${ }^{1}$ Antes ou após o início dos tratamentos. Médias seguidas pela mesma letra minúscula na coluna e maiúscula na linha não diferem entre si, pelo teste "t", a 5\% de probabilidade. 
TABELA 3 - Efeito de tratamentos na incidência (em porcentagem) de Monilinia fructicola em flores e frutos, na cultura do pessegueiro cv. Chimarrita, cultivado em sistema orgânico. Rio do Sul-SC, 2004.

\begin{tabular}{|c|c|c|c|c|c|c|}
\hline \multirow{2}{*}{ Tratamentos } & \multicolumn{2}{|c|}{ Floração } & \multirow{2}{*}{$\begin{array}{l}\text { Frutos } \\
\text { verdes }\end{array}$} & \multirow[t]{2}{*}{ Colheita } & \multicolumn{2}{|c|}{ Pós-colheita } \\
\hline & Antes $^{1}$ & Após $^{1}$ & & & $\begin{array}{c}\text { Sem } \\
\text { desinfestação }\end{array}$ & Desinfestados \\
\hline 1- Calda Sulfocálcica e Iodo & $38 \mathrm{a}$ & $11 b$ & $10 \mathrm{~b}$ & $54 \mathrm{a}$ & $73 \mathrm{~b}$ & $67 \mathrm{a}$ \\
\hline $\begin{array}{l}\text { 2- Calda Sulfocálcica e Iodo, } \\
\text { Fosfitos de CaB e de K, } \\
\text { Trichothecium roseum }\end{array}$ & $37 \mathrm{a}$ & $11 \mathrm{~b}$ & $13 \mathrm{~b}$ & $34 \mathrm{a}$ & $80 \mathrm{ab}$ & $60 \mathrm{a}$ \\
\hline 3- Trichothecium roseum & $32 \mathrm{a}$ & $6 \mathrm{~b}$ & $7 \mathrm{~b}$ & $38 \mathrm{a}$ & $73 \mathrm{~b}$ & $73 \mathrm{a}$ \\
\hline 4- Testemunha & $29 \mathrm{a}$ & $22 \mathrm{a}$ & $30 \mathrm{a}$ & $61 \mathrm{a}$ & $90 \mathrm{a}$ & $67 \mathrm{a}$ \\
\hline Média & & & & & $79 \mathrm{~A}$ & $67 \mathrm{~B}$ \\
\hline CV $(\%)$ & 41,7 & 26,9 & 46,0 & 23,2 & 2,0 & 12,4 \\
\hline
\end{tabular}

${ }^{1}$ Antes ou após o início dos tratamentos. Médias seguidas pela mesma letra minúscula na coluna e maiúscula na linha não diferem entre si, pelo teste "t", a 5\% de probabilidade.

TABELA 4 - Valores da análise de regressão multilinear $(R)$ e $(p)$ e correlações (r) entre a incidência da Podridão-Parda nas diferentes fases da cultura do pessegueiro, Cultivares Granada e Chimarrita, 2004.

\begin{tabular}{lcccccc}
\hline \multirow{2}{*}{ Fases da cultura } & \multicolumn{3}{c}{ Cv. Granada } & \multicolumn{3}{c}{ Cv. Chimarrita } \\
\cline { 2 - 7 } & $R$ & $P$ & $\mathrm{r}$ & $R$ & $p$ & $\mathrm{r}$ \\
\hline Flor x frutos verdes & 0,67 & $0,01{ }^{*}$ & 0,94 & 0,67 & $0,01^{*}$ & 0,98 \\
Flor x colheita & 0,11 & $0,09 \mathrm{~ns}$ & 0,80 & 0,18 & $0,56 \mathrm{~ns}$ & 0,77 \\
Flor x pós-colheita & 0,56 & $0,05 \mathrm{~ns}$ & 0,91 & 0,18 & $0,57 \mathrm{~ns}$ & 0,83 \\
Fruto verde x colheita & 0,18 & $0,57 \mathrm{~ns}$ & 0,83 & 0,56 & $0,37 \mathrm{~ns}$ & 0,68 \\
Fruto verde x pós-colheita & 0,67 & $0,02 *$ & 0,85 & 0,18 & $0,57 \mathrm{~ns}$ & 0,84 \\
\hline
\end{tabular}

\section{CONCLUSÕES}

1. Os tratamentos com calda sulfocálcica e iodo, antagonista Trichothecium roseum e a associação destes com fosfitos de $\mathrm{CaB}$ e de $\mathrm{K}$ são eficientes para a redução da queima das flores na fase de floração e da podridão-parda em frutos verdes, nas duas cultivares avaliadas.

2. Os tratamentos da forma como aplicados não foram eficientes para o controle da podridão-parda na colheita.

\section{REFERÊNCIAS}

ALMIRI, A.; BRANNEN, P. M.; SCHNABEL, G. Reduced sensitivity in Monilinia fructicola field isolates from South Carolina and Georgia to respiration inhibitor fungicides. Plant Disease, St Paul, v.94, p.737-743, 2010.

BYRDE, R.J.W.; WILLETTS, H.J. Infection. In: The brown rot of fruit: their biology and control. Oxford: Pergamon Press, 1977. p. 87-110. 
CRUICKSHANK, R.H.; WADE, G.C. The activation of latent infections of Monilinia fructicola on apricots by volatiles from the ripening fruit. Journal of Phytopathology, Berlin, v.136, n.2, p.107-112, 1992.

EMERY, K.M.; MICHAILIDES, T.J.; SCHERM, H. Incidence of latent infection of immature peach fruit by Monilinia fructicola and relationship to brown rot in Georgia. Plant Disease, St. Paul, v.84, n.8, p.853-857, 2000.

EMERY, K.M.; SCHERM, H.; SAVELLE, A.T. Assessment of interactions between components of fungicid mixtures against Monilinia fructicola. Crop Protection, Guildford, v. 21, n.1. p.41-47, 2002. FENN, M.E.; COFFEY, M.D. Further evidence for direct mode of action of phosethyl-al and phosphorous acid. Phytopathology, St. Paul, v.75, n.8, p.1064-1068, 1985.

GELL, I.; DE CAL, A.; TORRES, R.; USALL, J.; MELGAREJO, P. Conidial density of Monilinia spp. on peach fruit surfaces in relation to the incidences of latent infections and brown rot. European Journal of Plant Pathology , Dordrecht, v.123, n.4, p. 415424, 2008.

GEELEN, J.A. An evaluation of Agrio-Fos Supra 400 for the control of black spot and powdery mildew of apple in Hawke's Bay. New York: Geelen Research Independent Horticultural Consulants, 1999. $15 \mathrm{p}$.

GONÇALVES, P.A.S.; DEBARBA, J.F.; KESKE, C. Incidência da mosca-das-frutas, Anastrepha fraterculus (Diptera: Tephritidae), em cultivares de ameixa conduzidas sob sistema orgânico. Revista de Ciências Agroveterinária, Lages, v.4, n.2, p.101108, 2005.

HOLB, I.J.; SCHNABEL, G. The benefits of combining elemental sulfur with a DMI fungicide to control Monilinia fructicola isolates resistant to propiconazole. Pest Management Science, Sussex, v. 64, p.156-164, 2008.

HONG, C.; MICHAILIDES, T.J.; HOLTZ, B.A. Effects of wounding, inoculum density, and biological control agents on postharvest Brown rot of stone fruit. Plant Disease, St. Paul, v.82, n.11, p.12101216,1998
JACKSON, T.J.; BURGESS, T.; COLQUHOUN, I.; FORTE, G.E. StJ. Action of the fungicide phosphite on Eucaliptus marginata inoculated with Phytophthora cinnamomi. Plant Pathology, Oxford, n.1, v.49, p.147-154, 2000.

LARENA, I.; TORRES, R.; De CAL, A.; LIÑÁN, M.; MELGAREJO, P.; DOMENICHINI P.; BELLINI, A.; MANDRIN, J.F.; LOCHOU, J.; de ERIBE, X. O.; USALL, J. Biological control of postharvest Brown rot (Monilinia sp.) of peaches by field applications of Epicoccum nigrum. Biological Control, Orlando, v.32, n.1, p.305-310, 2005.

LUO, Y.; MORGAN, D.P.; MICHAILIDES, T.J. Risk analysis of rot blossom blight of prune caused by Monilinia fructicola. Phytopathology, St. Paul, v.91, n.8, p.759-768, 2001.

LUO, Y.; MICHAILIDES, T.J. Threshold conditions that lead latent infection to prune fruit rot caused by Monilinia fructicola. Phytopathology, St. Paul, v.93, n.1, p.102-111, 2003.

MAY-DE MIO, L. L.; AMORIM, L.; FAYAD, F. Susceptibility of peaches (cv. Chimarrita) at different ages to Monilinia fructicola infection. St Paul: American Phytopatological Society, v.98, p.100, 2008a.

MAY-DE MIO, L.L.; MOREIRA, L.M.; MONTEIRO, L.B.; JUSTINIANO JÚNIOR, P.R. Infecção de Monilinia fructicola no período da floração e incidência de Podridão-Parda em frutos de pessegueiro em dois sistemas de produção. Tropical Plant Pathology, Brasília, v.33, n.3, p.227-234, 2008b.

MERCIER, J.; JIMÉNEZ, J.I. Control of fungal decay of apples and peaches by the biofumigant fungus Muscodor albus. Postharvest Biology and Technology, Amsterdam, v.31, p. 1-8, 2004.

MOREIRA, L.M.; MAY-DE MIO, L.L.; VALDEBENITO-SANHUEZA, R.M.; LIMA, M.L.R.Z.C.; POSSAMAI, J.C. Controle em Pós-Colheita de Monilinia fructicola em Pêssegos. Fitopatologia Brasileira, Brasília, v.27, n.4, p.395-398, 2002.

MOREIRA, L.M. Alternativas de controle integrado da Podridão-Parda do pessegueiro. 2005. 113f. Tese (Doutorado em produção vegetal) - Universidade Federal do Paraná, Curitiba, 2005. 
MOREIRA, L.M.; MAY-DE MIO, L.L. Controle da Podridão-Parda do pessegueiro com fungicidas e fosfitos avaliados em pré e pós-colheita. Ciência e Agrotecnologia, Lavras, v.33, n.2, p.405-411, 2009.

NOJOSA, G.B.A.; RESENDE, M.L.V.; RESENDE, A.V. Uso de fosfitos e silicatos na indução de resistência. In: CAVALCANTI, L.S.; DI PIERO, R.M.; CIA, P.; PASCHOLATI, S.F.; RESENDE, M.L.V.; ROMEIRO, R.S. Indução de resistência em plantas a patógenos e insetos. Piracicaba: FEALQ, 2005. p. 139-153.

NORTHOVER J.; CERKAUSKAS R.F. Detection and significance of symptomless latent infections of Monilinia fructicola in prums. Canadian Journal of plant pathology, Ottawa, v.16, n.1, p.30-36, 1994.
RASEIRA, M.C.B.; NAKASU, B.H. Cultivares. In: RASEIRA, M.C.B.; CENTELLAS-QUEZADA, A. Pêssego, produção. Pelotas: Embrapa Clima Temperado, 2003. p.41-59.

REUVENI, M. Control of moldy-core decay in apple fruits by $\beta$-aminobutyric acids and potassium phosphites. Plant Disease, St Paul, v.87, p.933-936, 2003.

SÔNEGO, O.R.; GARRIDO, L. da R. Avaliação da eficácia de algumas marcas comerciais de fosfito de potássio e de fosfonato de potássio no controle do míldio da videira. Bento Gonçalves: EMBRAPA, 2005. (Circular Técnica,.60). 